\title{
TIMING OF OPERATIVE MANAGEMENT IN PATIENTS WITH TRAUMATIC CENTRAL CORD SYNDROME
}

\author{
Dimitar Haritonov, Svetoslav Kalevski, Nikolay Peev, Evgenia Kalevska \\ Department of Neurosurgery, University Hospital St. Anna, \\ Medical University of Varna
}

\begin{abstract}
OBJECTIVES: Patients with traumatic central cord syndrome (TCCS) provide some of the most dramatic opportunities for neurological improvement when compared to other subgroups of SCI, particularly evident in young patients with TCCS. The purpose of this study is to review a series of patients with central cord syndrome and to corroborate the consensus about optimal treatment and surgical timing for decompression.

MATERIALS AND METHODS: Patients developing this suffering belong to two relative categories - the first group are relatively young patients with a high-energy injury that leads to fracture/subluxation or dislocation. The second category are older individuals who, due to a low-energy fall or cervical hyperextension injury present with TCCS that occurs in the presence of cervical spondylosis but without obvious injury to the spinal column. The main tool for refinement of the operative window was ASIA motor score.

RESULTS: Thirty-two patient were divided in two groups - patients with ASIA motor score less than or equal to 50 p. (mean - 42.4 p.) - 10, and patients with a score higher than 50 p. (mean - 67.45 p.) - 22. Patients with ASIA M scores less than 50 p. were operated within 24 hours, but 2 patients from these - within 20 days. Patients with ASIA M score higher than 50 p. underwent decompression within 72 hours. All patients sustained improvement in neurological status with the exception of these two, who underwent late decompression.
\end{abstract}

DISCUSSION: These cases clearly demonstrate to what range should operative activity be targeted in patients with TCCS. Patients with ASIA M score 80 and above, with MRI fracture evidence and those who may have already experienced significant motor improvement between the time of injury and the moment of initial neurological evaluation, may undergo delayed surgical treatment.

CONCLUSIONS: There was a recommendation based on low-quality evidence that early (as soon as feasible) surgical decompression for patients with TCCS and spondylosis should be recommended when their initial neurological impairment is significant.

Keywords: traumatic central cord syndrome, spinal cord injury, spinal decompression

Address for correspondence:

Dimitar Haritonov, MD

Department of Neurosurgery,

University Hospital St. Anna,

Medical University of Varna

55 Marin Drinov Str.

9002 Varna, Bulgaria

e-mail:dgharitonov@gmail.com

Received: December 7, 2014

Accepted: December 19, 2014

\section{INTRODUCTION}

Traumatic central cord syndrome is the most common incomplete cervical cord lesion and accounts for up to $70 \%$ of all incomplete cervical cord injuries $(1,2)$. It is classically described as disproportionately more upper extremity weakness than lower extremity involvement, bladder dysfunction, and variable sensory loss below the involved level (3). Most studies indicate that patients have significant 
neurologic recovery with variable functional recovery (2-16). Recovery after traumatic central cord syndrome has been related to a number of prognostic factors, including initial American Spinal Injury Association (ASIA) $(13,16)$, magnetic resonance imaging (MRI) evidence of spinal cord edema and hemorrhage $(1,17,18)$, the patient's age $(13,15,19,20)$, good hand function (1), absence or presence of spasticity $(2,13,15)$, and type of injury (11). Although these factors have been identified by various studies, no research has yet incorporated these elements into a classification system that is predictive of functional recovery. The purpose of this article is to present optimal operative timing of traumatic central cord syndrome that should lead to maximal functional recovery and outcome.

\section{Patients and Methodology}

Between 2006 and 201037 patients, who developed this suffering after hyperextension injury, were presented with TCCS that occurs in the presence of cervical spondylosis, but without obvious injury to the spinal column. Neurologic assessment was performed by spine service and included history, physical examination, computed tomography scans of the cervical spine and MRI of the spine. Patients were diagnosed with central cord syndrome if they had cervical spinal cord injury with disproportionately more weakness in the upper extremities than lower extremities and sacral pinprick or voluntary motor sparing. The main tools for refinement of neurologic assessment were ASIA Impairment Scale and SLIC and MRI evidence in T2-weighted sagittal imaging for spinal cord injury and oedema (Fig. 1, 2). 29 patients were in admission with an ASIA D level and the other group of 8 patients were with an ASIA C level.

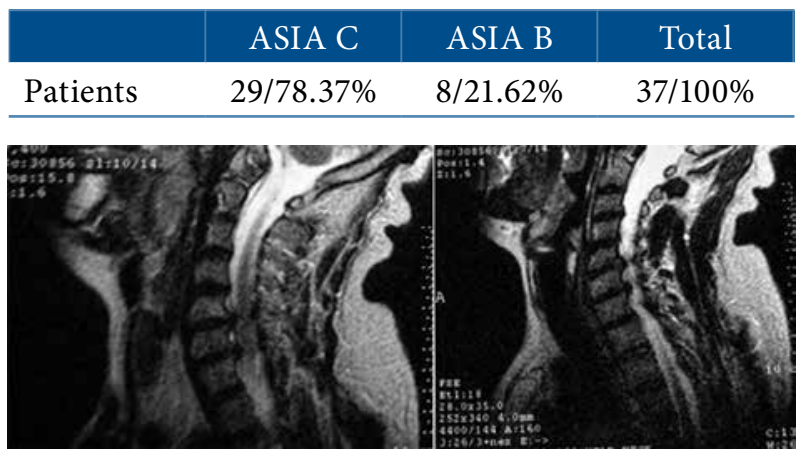

Fig. 1. T2-weighted magnetic resonance imaging of a 58-year-old male with severe cervical spondylosis and incomplete spinal cord injury - TCCS.

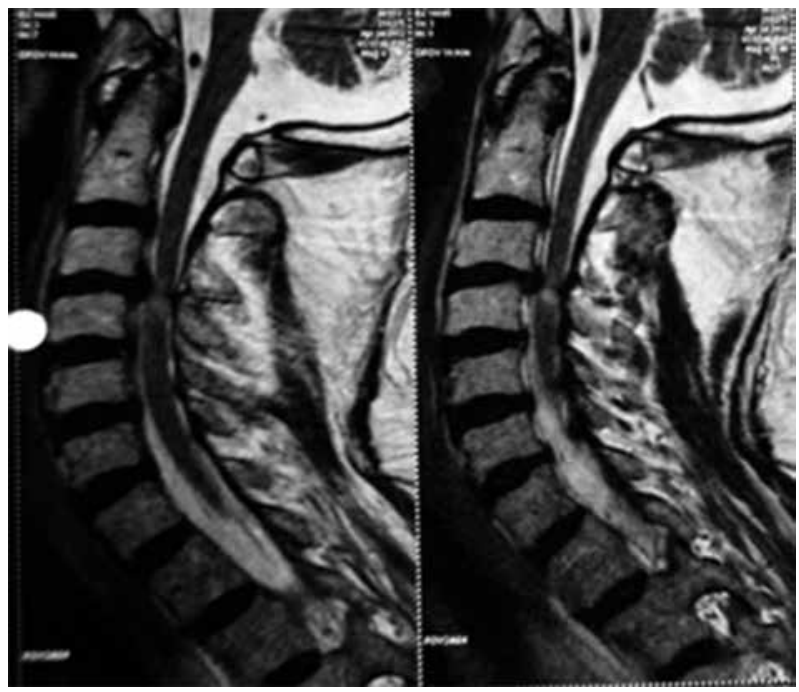

Fig. 2. Acute traumatic cervical disk herniation at the level C3-C4 in T2-weighted magnetic resonance imaging of a

52-year-old male who presented with moderate TCCS

In all of the 37 patients anterior surgery and fusion with cage and plate were performed (Fig. 3).

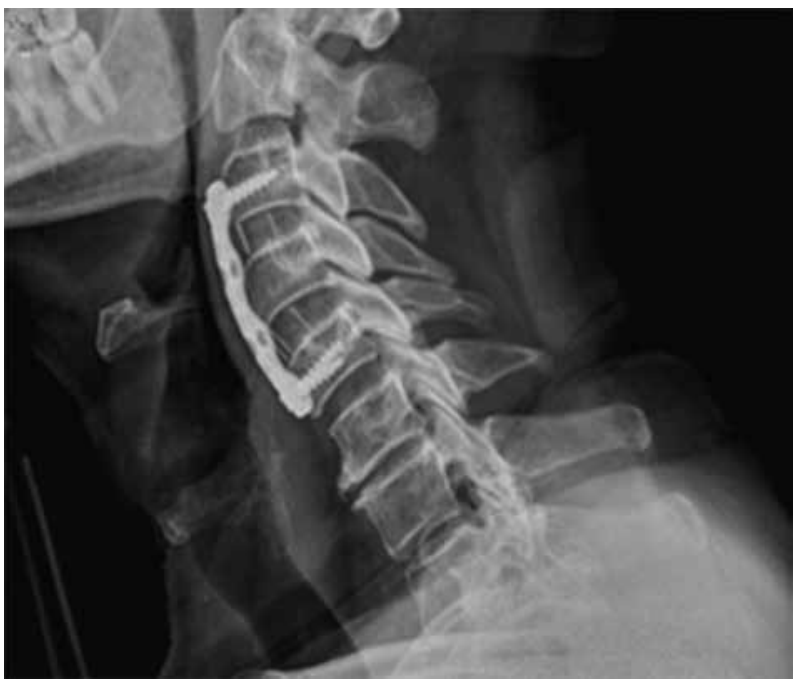

Fig. 3. One year post OP - ACDF and plating, adjacent level degeneration

Operative timing was split in two intervals early operative management within 24 hours and delayed operative management ( $>24$ hours). The candidates for early surgery were patients with a spinal cord compression - traumatic disc herniation and no neurological improvement during the initial 24 hours. The other group of operative cases who presented with delayed surgery were patients with severe cervical spondylosis, without spinal cord com- 
pression and neurologic improvement in the initial 24-36 hours.

\section{DISCUSSION}

The fundamental question that the treating surgeon has to answer is whether to operate acutely or to consider an initial period of nonsurgical treatment. This question has two components, the first relating to whether there is a benefit to surgical decompression in this population and the second to the potential timing of this intervention. If the timing of surgery is not relevant, then it is most reasonable to observe the patients' motor and sensory function for as long as they continue to make neurological gains, and to reserve surgery for those patients whose spontaneous neurological improvement ceases or plateaus at a non-functional level. In the study of Guest et al. (12) only those patients without spondylosis/stenosis had improved motor recovery resulting from early surgery. Yamazaki et al (33) observed that there were no benefits from a conducted intervention unless within 2 weeks. Other authors introduced a recommendation for surgery if there was TCCS in the presence of compressive lesions and no improvement within 4 weeks. When the surgical cohort was further stratified into early (within 2 weeks; mean 8 days) and late (after 2 weeks; mean 30 days) intervention, the patients in the early surgery group, despite having worse JOA score (8.7) and narrower AP diameter $(8.8 \mathrm{~mm})$, exhibited greater recovery ( $80 \%)$ than the late surgery group (48\%) and this was interpreted by the authors as a compelling argument for early surgery. Dai and Jia (10) reported retrospectively reviewed 24 patients with disk herniation causing acute CCS. All patients had anterior decompression and good neurological improvement. Uribe et al (34) in a paper that presents the results of posterior laminoplasty in a group of patients with TCCS and cervical spondylosis, reported on the results of early (mean -3 days post injury) surgery in 15 patients. By reporting early postoperative neurological improvement in all patients, the paper by Uribe et al has provided high quality evidence in support of early surgery.

\section{CONCLUSION}

In this prospectively collected retrospective review of 37 patients with traumatic central cord syndrome, 3 factors were predictive of one year func- tional outcome: ASIA Motor Score at the time of injury, MRI evidence of abnormal signal intensity and steroid administration at the time of injury. ASIA Motor Score and MRI evidence of abnormal signal intensity were used to create a predictive classification system called Central Cord Injury Scale (CCIS). Surgery is recommended when patients with TCCS have compressive lesions and expressed spondylosis.

\section{REFERENCES}

1. Merriam WF, Taylor TK, Ruff SJ, et al. A reappraisal of acute traumatic central cord syndrome. J Bone Joint Surg Br. 1986;68:708-13.

2. Bosch A, Stauffer S, Nickel VL. Incomplete traumatic quadriplegia. A tenyear review. JAMA. 1971;216:473-8.

3. Schneider RC, Cherry G, Pantek H. The syndrome of acute central cervical spinal cord injury, with special reference to the mechanics involved in hyperextension injuries of the cervical spine. J Neurosurg. 1954;11:546 -77.

4. Bridle MJ. Long term function following the central cord syndrome. Paraplegia. 1990;28:178-85.

5. Newey ML, Sen PK, Fraser RD. The long-term outcome after central cord syndrome: a study of the natural history. J Bone Joint Surg Br. 2000;82:851-5.

6. Bose B, Northrup BE, Osterholm JL, et al. Reanalysis of central cervical cord injury management. Neurosurgery. 1984;15:367-72.

7. Brodkey JS, Miller CF Jr, Harmody RM. The syndrome of acute central cervical spinal cord injury revisited. Surg Neurol. 1980;14:251-7.

8. Chen TY, Lee ST, Lui TN, et al. Efficacy of surgical treatment in traumatic central cord syndrome. Surg Neurol. 1997;48:435-40.

9. Chen TY, Dickman CA, Eleraky M, et al. The role of decompression for acute incomplete cervical spinal cord injury in cervical spondylosis. Spine. 1998;23:2398 - 403 .

10. Dai L, Jia L, Ni B, et al. Diagnosis and treatment of acute central cervical cord injury. Chin Med J (Engl). 1998;111:351-3.

11. Dai L, Jia L. Central cord injury complicating acute cervical disc herniation in trauma. Spine. 2000;25:331-5.

12. Guest J, Eleraky MA, Apostolides PJ, et al. Traumatic central cord syndrome: results of surgical management. J Neurosurg. 2002;97:25-32. 
Dimitar Haritonov, Svetoslav Kalevski, Nikolay Peev et al.

13. Roth EJ, Lawler MH, Yarkony GM. Traumatic central cord syndrome: clinical features and functional outcomes. Arch Phys Med Rehabil. 1990;71:18 -23.

14. Shrosbree RD. Acute central cervical spinal cord syndrome-aetiology, age incidence and relationship to the orthopaedic injury. Paraplegia. 1977;14: 251-8.

15. Tow AM, Kong KH. Central cord syndrome: functional outcome after rehabilitation. Spinal Cord. 1998;36:156-60.

16. Dvorak MF, Fisher CG, Hoekema J, et al. Factors predicting motor recovery and functional outcome after traumatic central cord syndrome: a long term follow up. Spine. 2005;30:2303-11.

17. Ishida Y, Tominaga T. Predictors of neurologic recovery in acute central cervical cord injury with only upper extremity impairment. Spine. 2002;27:1652-7.

18. Seldon NR, Quint DJ, Patel N, et al. Emergency magnetic resonance imaging of cervical spinal cord injuries: clinical correlation and prognosis. Neurosurgery. 1999;44:785-92.

19. Penrod LE, Hegde SK, Ditunno JF Jr. Age effect on prognosis for functional recovery in acute, traumatic central cord syndrome. Arch Phys Med Rehabil. 1990;71:963-8.

20. Rand RW, Crandall PH. Central cord syndrome in hyperextension injuries of the cervical spine. J Bone Joint Surg Am. 1962;44:1415-22.

21. Granger CV, Hamilton BB, Linacre JM, et al. Performance profiles of the functional independence measure. Am J Phys Med Rehabil. 1993;72:84-9.

22. Karamehmetoglu SS, Karacan I, Elbasi N, et al. The functional independence measure in spinal cord injured patients: comparison of questioning with observational rating. Spinal Cord. 1997;35:22-5.

23. Stineman MG, Hamilton BB, Goin JE, et al. Functional gain and length of stay for major rehabilitation impairment categories: patterns revealed by function related groups.Am J Phys Med Rehabil. 1996;75:68-78.

24. Curt A, Keck ME, Dietz V. Functional outcome following spinal cord injury: significance of motor evoked potentials and ASIA scores. Arch Phys Med Rehabil. 1998;79:81-6.

25. Miyanji F, Furlan JC, Aarabi B, et al. Acute cervical traumatic spinal cord injury: MR imaging findings correlated with neurologic outcome - prospec- tive study with 100 consecutive patients. Radiology. 2007;243:820 -7.

26. Dai L. Magnetic resonance imaging of acute central cord syndrome: correlation with prognosis. Chin Med Sci J. 2001;16:107-10.

27. Schaeffer DM, Flanders A, Northrup BE, et al. Magnetic resonance imaging of acute cervical spine trauma. Correlation with severity of neurologic injury. Spine. 1989;14:1090-5.

28. Shepard MJ, Bracken MB. Magnetic resonance imaging and neurological recovery in acute spinal cord injury: observations from the National Acute Spinal Cord Injury Study 3. Spinal Cord. 1999;37:833.

29. Rao SC, Fehlings MG. The optimal radiologic method for assessing spinal canal compromise and cord compression in patients with cervical spinal cord injury. I. An evidence-based analysis of the published literature. Spine. 1999;24:598-604.

30. Fehlings $\mathrm{MG}$, Rao SC, Tator $\mathrm{CH}$, et al. The optimal radiologic method for assessing spinal canal compromise and cord compression in patients with cervical spinal cord injury. II. Results of a multicenter study. Spine. 1999;24:605-13.

31. Fehlings MG, Furlan JC, Massicotte EM, et al. Interobserver and intraobserver reliability of maximum canal compromise and spinal cord compression for evaluation of acute traumatic cervical spinal cord injury. Spine. 2006;31:1719-25.

32. Furlan JC, Fehlings MG, Massicotte EM, et al. A quantitative and reproducible method to assess cord compression and canal stenosis after cervical spine trauma: a study of interrater and intrarater reliability. Spine. 2007;32:2083-91.

33. Yamazaki T, Yanaka K, Fujita K, et al. Traumatic central cord syndrome: analysis of factors affecting the outcome. Surg Neurol. 2005;63(2):95-99;discussion 9-100.

34. Uribe J, Green BA, Vanni S, et al. Acute traumatic central cord syndrome-experience using surgical decompression with open door expansive cervical laminoplasty. Surg Neurol. 2005;63(6):505-510; discussion 10 . 